\title{
PENGEMBANGAN DASHBOARD EKSEKUTIF UNTUK SISTEM MONITORING PENANGANAN FILARIASIS KOTA PEKALONGAN
}

\author{
Mohammad Reza Maulana'), Eko Budi Susanto ${ }^{2)}$, Paminto Agung Christianto ${ }^{3)}$ \\ 1,2,3 STMIK Widya Pratama Pekalongan \\ Email : ${ }^{1}$ reza.stmikwp@gmail.com, ${ }^{2}$ eqo bs@yahoo.com, ${ }^{3}$ agung.chr@gmail.com
}

\begin{abstract}
Pekalongan City still has a Microfilaria Rate of more than one percent based on a survey from 2011 to 2015. This causes the Pekalongan City Health Office to repeat POPM activities for the next two years. It is hoped that this incident will not be repeated in the following years. One of the obstacles faced is the absence of monitoring in the administration of elephantiasis medicine. In general, elephantiasis medication has been given well, but the community's level of adherence to taking filiaris medication is still low. So that the efforts that have been made by the Health Office have not been able to break the chain of filariasis disease. One solution to this problem is to apply the $R T / R W$ executive dashboard application which in previous research has been developed in the form of a prototype. In this study, a prototype of the RT/RW executive dashboard will be developed so that it can be used to carry out monitoring activities for filariasis drug administration.
\end{abstract}

Keywords: Executive dashboard, filariasis, prototype

\section{PENDAHULUAN}

Kota Pekalongan adalah salah satu kota di Jawa Tengah, yang masih endemis filariasis/penyakit kaki gajah. Berdasarkan hasil evaluasi atau Pre TAS (Transmissions Assesment Survey) yang dilakukan oleh Kementerian Kesehatan RI pada tanggal 11-13 November 2015, di Kelurahan Jenggot Kota Pekalongan ditemukan 3 (tiga) orang positif dari 300 (tiga ratus) sampel. Nilai rata-rata mikrofilaria (MF Rate) pada Kelurahan Jenggot lebih dari $1 \%$ (MF rate > 1\%). Berdasarkan hal tersebut Kota Pekalongan harus mengulang Pemberian Obat Pencegahan Massal (POPM) selama 2 (dua) tahun, yaitu: tahun 2017 dan 2018. Hasil evaluasi oleh Kementerian Kesehatan RI tahun 2018 di Kelurahan Jenggot masih memiliki $M F$ rate $>1 \%$. Dengan demikian Kota Pekalongan masih memiliki risiko penularan filariasis yang tinggi. Berdasarkan hasil evalusi tersebut Kota Pekalongan masih harus melakukan POPM pada tahun 2020 dan 2021 (hasil wawancara dengan Dinas Kesehatan Kota Pekalongan).
Sejak tahun 2011, Kota Pekalongan sudah memberikan obat massal pencegahan filariasis, namun menurut Kepala Dinas Kesehatan Kota Pekalongan (Slamet Budiyanto), tingkat kepatuhan minum obat filariasis masyarakat masih rendah, sehingga masih ditemukan beberapa kelurahan yang memiliki endemis filariasis.

Dinas Kesehatan Kota Pekalongan sudah memberikan langkah preventif dalam menghadapi kasus filariasis, yaitu dengan memberikan obat filariasis. Pembagian obat filariasis dilakukan melalui kader dari Puskesmas. Pemberian obat filariasis kepada masyarakat saat ini dilakukan dengan cara membagikan kepada masyarakat, akan tetapi kader dari Puskesmas tidak mengetahui apakah obat tersebut benar-benar dikonsumsi setelah dibagikan. Proses monitoring harus dilakukan dengan ketat agar masyarakat meminum obat filariasis yang telah dibagikan.

Berdasarkan permasalahan tersebut di atas salah satu solusi yang diberikan adalah dengan membuatkan aplikasi yang dapat memonitoring 
pemberian obat filariasis. Pada penelitian sebelumnya telah dikembangkan prototipe Dashboard Eksekutif RT/RW (Maulana, Syaifudin, Budijanto, \& Susanto, 2021). Dashboard Eksekutif RT/RW merupakan sebuah tampilan informasi (user interface) berbentuk grafis yang memberikan visualisasi performance dengan menggunakan indikatorindikator tertentu sebagai dasar tampilan informasi.

Prototipe Dashboard Eksekutir RT/RW yang akan dikembangkan berikutnya dapat mendokumentsikan warga atau masyarakat pada saat meminum obat filariasis. Dengan demikian Dinas Kesehatan dapat memastikan obat filariasis yang diberikan telah diminum, sehingga diharapkan dapat meningkatkan tingkat kepatuhan masyarakat dalam memium obat fialirasis.

Pada penelitian sebelumnya yang dilakukan oleh Dewi dkk (Dewi, Ahmadi, \& Suardika, 2015), mengembangkan Dashboard Executive Information System pada Desa Banjar Kabupaten Buleleng berbasis Web di Provinsi Bali. Hasil dari penelitian tersebut didapatkan bahwa aplikasi dapat mempermudah pencarian informasi-informasi yang ada pada Kabupaten Banjar sehingga dapat meminimalkan waktu yang diperlukan, mempermudah user dalam melihat data-data penduduk secara visual. Pada penelitian lain yang dilakukan oleh Yudiantara, dkk (Yudiantara, Sukarsa, \& Sutramiani, 2019), membangun Dashboard Executive Information System dengan Pendekatan Sistem Terdistribusi untuk Pemantauan Penyaluran Kredit KUR Mikro Bank X. Hasil dari penelitian tersebut, yaitu sistem dapat melakukan sinkronisasi data nasabah antar kantor unit, adanya grafik untuk menyajikan perbandingan jumlah nasabah, penerapan teknologi web service yang mendukung pertukaran data secara real-time, serta sinkronisasi dua arah antar kantor unit yaitu insert, update, delete dan read dari database.

Oleh karena itu, dengan terwujudnya dashboard eksekutif monitoring pemberian obat filariasis, maka Pemerintah Kota Pekalongan khususnya Dinas Kesehatan Kota Pekalongan dapat memastikan bahwa obat filariasis yang telah diberikan kepada warga atau masyarakat telah diminum serta dapa melihat dan memonitoring data real-time di lapangan, sehingga jika ada hal yang tidak sesuai maka dapat cepat teratasi.

\section{TINJAUAN PUSTAKA}

\subsection{Angka Mikro Filariasis di Kota Pekalongan Lebih dari $1 \%$}

Penyakit kaki gajah atau filariasis masih menjadi penyakit endemis di Kota Pekalongan. Upaya telah dilakukan oleh Dinas Kesehatan Kota Pekalongan dengan memberikan obat filariasis kepada masyarkat sejak tahun 2011. Akan tetapi langkah ini masih belum optimal. Kota Pekalongan memiliki angka cakupan POPM (Pelaksanaan Pemberian Obat Pencegahan Secara Massal) masih di bawah 65\% (tahun 2011 hingga 2015), dan belum mencapai standar yang telah ditetapkan oleh Kementerian Kesehatan dalam memutus mata rantai penyakit filariasis. Hasil penelitian lima tahun berturut-turut menunjukkan angka Mikrofilaria Rate (MF rate) > 1\% dan harus mengulang POPM selama 2 tahun lagi (BP, Ginandjar, Kusariana, \& Saraswati, 2019).

Penyelenggaraan POMP yang dilakukan oleh Dinas Kesehatan Kota Pekalongan secara umum sudah baik, hal ini dapat dilihat dari indikator jumlah penerima obat yang jumlahnya lebih dari 90 persen. Akan tetapi dari 90 persen tersebut hanya 50 persen yang telah meminum obat filariasis yang diberikan. Dengan demikian dapat dikatakan kegiatan POPM belum mencapai target sehingga belum dapat memutus mata rantai penyakit filariasis (Dinkominfo Kota Pekalongan, 2017).

\subsection{Pengembangan Prototipe Dashboard RT/RW}

Pada penelitan sebelumnya peneliti telah mengembangkan Dahboard Eksekutif sebagai Media Koordinasi dan Monitoring Kegiatan untuk Peningkat Kinerja Aparatur Pemerintah (Maulana, Syaifudin, Budijanto, \& Susanto, 2021). Pada penelitian ini akan dikembangkan kembali untuk mendukung kesukseskan penyelenggaraan POMP yang dilakukan oleh Dinas Kesehatan Kota Pekalongan.

Adapun kebutuhan fungsional sistem yang diharapkan yaitu: 1) Sistem dapat mendokumentasikan dalam bentuk foto saat 
masyarakat meminum obat penyakit kaki gajah yang diberikan kader kesehatan setempat (data foto tersimpan di server); 2) Sistem dapat menerima inputan data dari kader kesehatan setelah itu memfoto masyarakat saat meminum obat penyakit kaki gajah; 3) Sistem dapat menginformasikan keaktifan kader kesehatan dalam memberikan obat ke masyarakat; dan 4) Sistem bersifat mobile, sehingga dapat diakses dari berbagai perangkat, termasuk smartphone.

\subsection{Dasar Hukum}

a. Undang-Undang Nomor 23 Tahun 2014 tentang Pemerintahan Daerah;

b. Undang-Undang Nomor 11 Tahun 2008 tentang Informasi dan Transaksi Elektronik;

c. Undang-Undang Nomor 14 Tahun 2008 tentang Keterbukaan Informasi Publik;

d. Undang-Undang Nomor 36 Tahun 2009 tentang Kesehatan;

e. Peraturan Pemerintah No. 46 Tahun 2014 tentang Sistem Informasi Kesehatan;

f. Peraturan Menteri Kesehatan RI No. 75 Tahun 2014 tentang Puskesmas;

g. Peraturan Menteri Kesehatan RI No. 92 tahun 2014 tentang Penyelenggaraan Komunikasi Data dalam Penyelenggaraan Sistem Informasi Kesehatan Terintegrasi;

h. Keputusan Menteri Kesehatan Nomor 511/Menkes/SK/V/2002 tentang Kebijakan dan Strategi Pengembangan SIK Nasional (SIKNAS);

i. Keputusan Menteri Kesehatan RI Nomor : 932/Menkes/SK/VIII/2002 tentang

Petunjuk Pelaksanaan Pengembangan Sistem Laporan Informasi Kesehatan Kabupaten / Kota;

j. Keputusan Menteri Kesehatan RI Nomor : 004/Menkes/SK/I/2003 tentang Kebijakan dan Strategi Desentralisasi Bidang Kesehatan;

\section{METODE PENELITIAN}

Aktivitas penelitian pada penelitian ini adalah sebagai berikut: 1) Pengumpulan Data; 2) Analisis Kebutuhan; 3) Desain Sistem; dan 4) Pembangunan Sistem; 5) Pengujian Sistem.

Pengumpulan data dilakukan dengan cara melakukan wawancara dengan Dinas Kesahatan Kota Pekalongan yaitu dengan Kepala Dinas
Kesehatan Kota Pekalongan dan Bidang Pencegahan dan Pengendalian Penyakit.

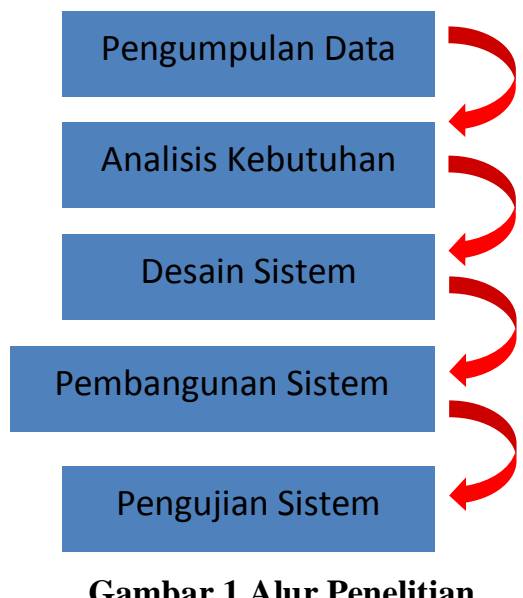

Analisis kebutuhan dilakukan setelah dilakukannya tahap pengumpulan data. Pada tahap analisis data ditentukan kebutuhan dari pengguna, kebutuhan fungsional sistem dan kebutuhan non-fungsional sistem.

Pada tahap desain sistem, dilakukan desain interface, desain database berdasarkan dari kebutuhan fungsional dan non-fungsional sistem. Pada tahap selanjutnya yaitu tahap pembangunan sistem. Pembangunan sistem dilakukan berdasarkan desain sistem yang telah dibuat.

Tahap terakhir yaitu pengujian sistem. Pengujian sistem dilakukan untuk memastikan apakah sistem yang sudah dibangun sudah sesuai dengan kebutuhan yang diharapkan oleh pengguna atau belum.

\section{HASIL DAN PEMBAHASAN}

\subsection{Pengumpulan Data}

Pengumpulan data dilakukan dengan cara:

1) Wawancara; 2) Pengamatan/observasi; dan

3) Studi leteratur. Hasil wawancara dengan Dinas Kesehatan Kota Pekalongan berkaitan dengan hasil evaluasi/pre TAS oleh Kementerian Kesehatan RI pada kegiatan POPM di Kota Pekalongan: 
Tabel 1 Hasil Evaluasi POPM Kota Pekalongan oleh Kemenkes RI

\begin{tabular}{|c|c|c|c|c|c|}
\hline No & Tahun & Metode & $\begin{array}{l}\text { Sampel } \\
\text { (orang) }\end{array}$ & Kelurahan & Hasil \\
\hline 1 & 2015 & $\begin{array}{c}\text { Pre TAS } \\
\text { (Transmissions } \\
\text { Assesment Survey) }\end{array}$ & 300 & Jenggot & $\begin{array}{ll}- & \text { MF Rate }>=1 \% \\
\text { - } & \text { Dari } 300 \text { sampel ditemukan } \\
& 3 \text { positif } \\
\text { - } & \text { Kota Pekalongan } \\
& \text { mengulang POPM selama } 2 \\
& \text { tahun (2017-2018) }\end{array}$ \\
\hline 2 & 2018 & $\begin{array}{c}\text { Survei Darah Jari } \\
\text { dengan metode ICT }\end{array}$ & 49 & Kuripan Kertoharjo & $\begin{array}{ll}- & \text { MF Rate }>=1 \% \\
- & \text { Dari } 49 \text { sampel ditemukan } 7 \\
& \text { positif }\end{array}$ \\
\hline 3 & 2019 & $\begin{array}{c}\text { Pre TAS } \\
\text { (Transmissions } \\
\text { Assesment Survey) }\end{array}$ & & $\begin{array}{l}\text { - Bendan Kergon } \\
\text { - Podosugih } \\
\text { - Medono } \\
\text { - Kandang Panjang }\end{array}$ & $\begin{array}{ll}- & \text { MF Rate }>=1 \% \\
- & \text { Kota Pekalongan } \\
& \text { mengulang POPM selama } 2 \\
& \text { tahun }(2020-2021)\end{array}$ \\
\hline
\end{tabular}

Sehubungan terjadi pandemi Covid-19, pelaksanaan POPM filariasis yang semula direncanakan tahun 2020 dan 2021, diundur menjadi tahun 2021 dan 2022.

Beberapa kendala yang dihadapi pada pelaksanaan POPM filariasis di Kota Pekalongan antara lain: 1) Masyarakat merasa sehat sehingga tidak perlu minum obat; 2) Sosialisasi POPM belum sampai pada semua lapisan masyarakat; 3) Pada saat pembagian obat oleh kader Tenaga Pelaksana Eliminasi (TPE), warga tidak berada di rumah; 4) Minum obat bersama membutuhkan biaya operasional untuk menyediakan air minum atau pisang; 5) Peran serta masyarakat belum optimal dalam mensukseskan kegiatan POPM; dan 6) Peran serta lintas sektor belum optimal.

Pemberian obat filariasis dilakukan dengan menugaskan kader TPE untuk memberikan obat filariasi di tiap kelurahan hingga lingkup RT dari pintu ke pintu rumah penduduk. Setiap kader TPE akan dikoordinir oleh Puskesmas di masing-masing kelurahan. Proses pencataan yang dilakukan kader TPE pada pemberian obat dilakukan dengan mencatat secara manual di form pendataan.

\subsection{Analisis Kebutuhan}

Dari hasil analisis kebutuhan didapatkan kebutuhan fungsional sistem, yaitu: sistem dapat melakukan import data dalam bentuk file *.xlsx untuk meng-update atau mengolah data, sistem dapat mendokumentasikan dalam bentuk foto saat masyarakat meminum obat penyakit kaki gajah yang diberikan kader kesehatan setempat (data foto tersimpan di server), sistem dapat menerima inputan data dari kader kesehatan setelah itu memfoto masyarakat saat meminum obat penyakit kaki gajah, sistem dapat menginformasikan keaktifan kader kesehatan dalam memberikan obat ke masyarakat, sistem bersifat mobile, sehingga dapat diakses dari berbagai perangkat, termasuk smartphone.

\subsection{Desain Sistem}

Penamaan Aplikasi Dashboard Eksekutif RT/RW yaitu: "Aplikasi Pendataan Pemberian Obat Filariasis kepada Masyarakat Kota Pekalongan". Pemberian nama ini merupakan hasil kesepakatan dengan pengguna aplikasi dalam hal ini Dinas Kesehatan Kota Pekalongan.

\subsubsection{Alur Bisnis Aplikasi}

4.3.1.1. Pra Pemberian Obat Filariasis

Kader Tenaga Pelaksana Eliminasi (TPE) mendata warga atau masyarakat di lingkungannya secara manual melalui form pendataan. Setelah data terkumpul, data diserahkan kepada koordinator di tingkat puskesmas untuk diinputkan ke dalam Dashboard Eksekutir RT/RW filariasis.

\subsubsection{Pemberian Obat}

Koordinator Puskesmas mendata jumlah obat yang akan diberikan berdasarkan data warga yang telah diinputkan di Dashboard Eksekutir RT/RW untuk kemudian Kader Tenaga Pelaksana Eliminasi (TPE) 
membagikan obat filariasis kepada warga. Pada saat membagikan obat kepada warga, Kader Tenaga Pelaksana Eliminasi (TPE) melakukan validasi data dan mengambil gambar warga saat minum obat filariasis

\subsubsection{Pengguna Aplikasi}

Pengguna aplikasi "Pendataan Pemberian Obat Filariasis kepada Masyarakat Kota Pekalongan" adalah Dinas Kesehatan, Puskesmas dan Kader Tenaga Pelaksana Eliminasi (TPE) dengan tingkatan user sebagaimana dalam tabel 2 berikut.

\section{Tabel 2 Pengguna Aplikasi}

\begin{tabular}{ccc}
\hline Pengguna & Platform Aplikasi & Level \\
\hline $\begin{array}{c}\text { Dinas } \\
\text { Kesehatan }\end{array}$ & Web Based & $\begin{array}{c}\text { Super } \\
\text { Admin }\end{array}$ \\
\hline Admin Dinkes & Web Based & Admin \\
\hline Puskesmas & Web Based & Admin \\
\hline Kader TPE & Mobile Android & Kader \\
\hline
\end{tabular}

\subsubsection{Proses Bisnis Aplikasi}

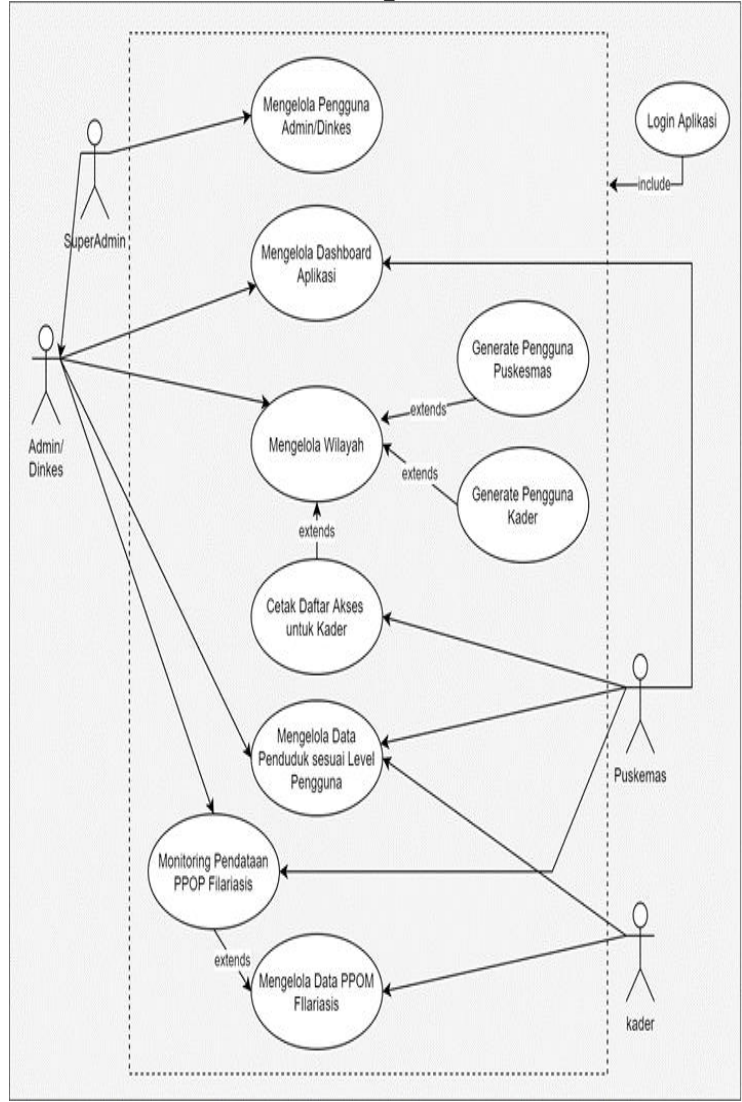

Gambar 2 Proses Bisnis Aplikasi

\subsubsection{Dinas Kesehatan sebagai Admin}

Kewenangan dari Dinas Kesehatan sebagai admin atau yang disebut pengguna "Dinkes Admin" antara lain: a. Login aplikasi;

b. Dashboard rekap data dalam bentuk grafik/diagram (dalam pengembangan);

c. Mengelola data wilayah (Kecamatan, Kelurahan, RW, RT);

d. Generate pengguna Puskesmas dan Kader;

e. Cetak data akses login untuk Kader;

f. Mengelola data penduduk;

g. Import data penduduk dari data *.xlsx; dan

h. Monitoring pemberian obat filariasis oleh Kader.

\subsubsection{Puskesmas}

Kewenangan pengguna "Admin Puskesmas" antara lain:

a. Login aplikasi;

b. Dashboard rekap data dalam bentuk grafik/diagram (dalam pengembangan);

c. Cetak data akses login untuk Kader;

d. Mengelola data penduduk;

e. Import data penduduk dari data *.xlsx;

f. Monitoring pemberian obat filariasis oleh Kader; dan

g. Melakukan cetak-cetak laporan (dalam pengembangan).

\subsubsection{Kader TPE}

Kewenangan pengguna "Kader TPE" antara lain:

1) Login aplikasi;

2) Dashboard rekap data "status minum";

3) Menambah data penduduk jika belum diinput oleh Admin/Puskesmas;

4) Mengelola data pemberian obat filariasis; dan

5) Melihat akun Kader; 


\subsubsection{Desain Database}

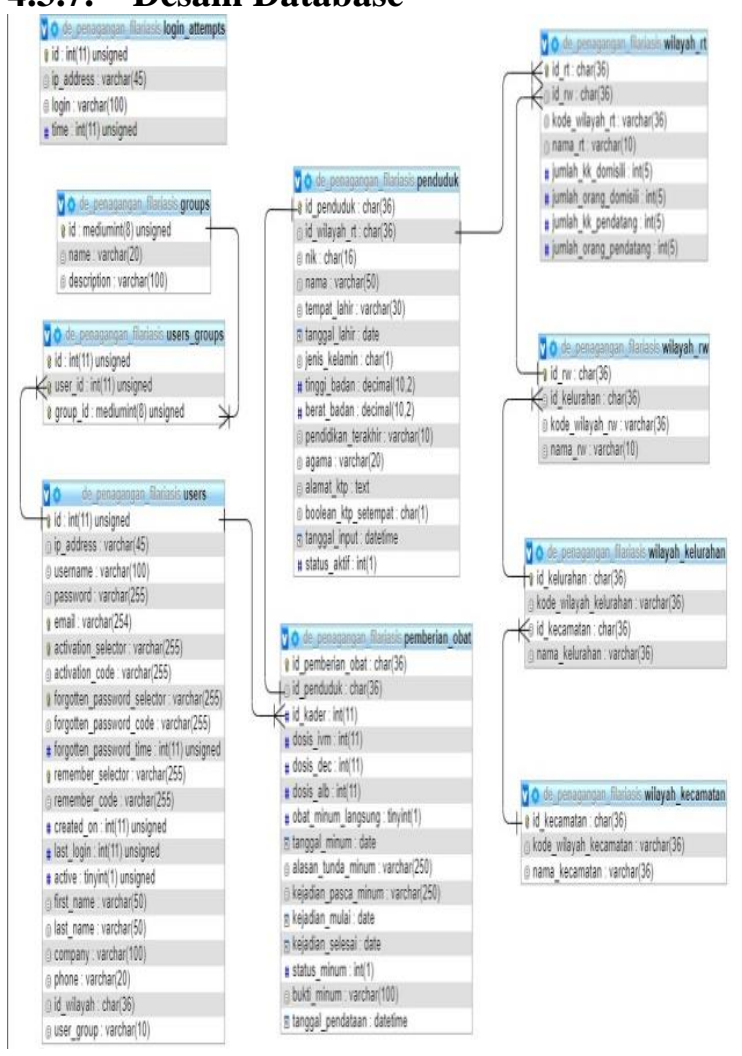

Gambar 3 Desain Database

\subsection{Pembangunan Sistem}

\subsubsection{Halaman Login}

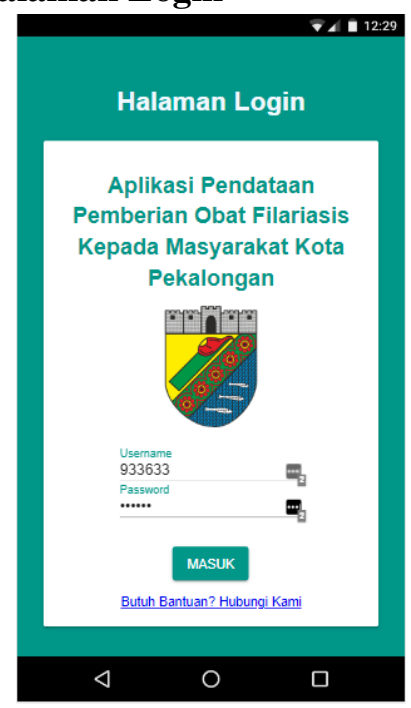

Gambar 4 Halaman Login

Halaman login (lihat gambar 4) digunakan untuk masuk ke dalam aplikasi. Username dan password kader TPE, diperoleh dari Admin Puskesmas atau Admin Dinkes.
Username dan password untuk kader TPE di-generate secara otomasi oleh sistem. Hanya pengguna Admin Puskesmas dan Admin Dinkes yang dapat melakukan generate username dan passwrod kader TPE

\subsubsection{Halaman Beranda}

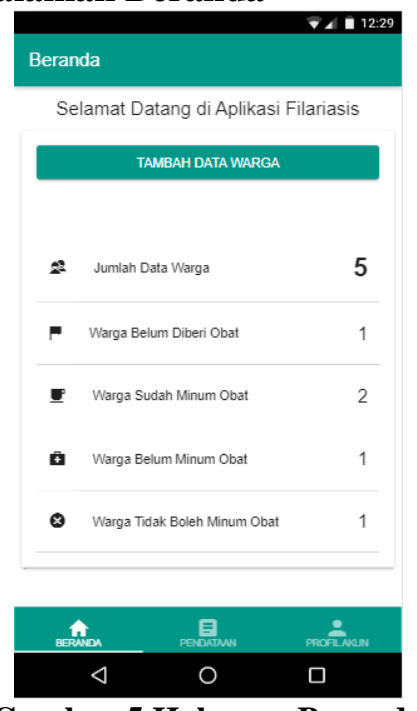

Gambar 5 Halaman Beranda

Halaman beranda (lihat gambar 5) berisi informasi jumlah data warga, warga yang belum diberi obat, warga yang sudah meminum obat, warga yang belum meminum obat, dan warga yang tidak boleh minum obat. Pengguna dapat mengetahui jumlah data warga yang menjadi tanggung jawab kader TPE dan Koordinator Puskesmas dalam pemberian obat filariasis.

\subsubsection{Halaman Pendataan}

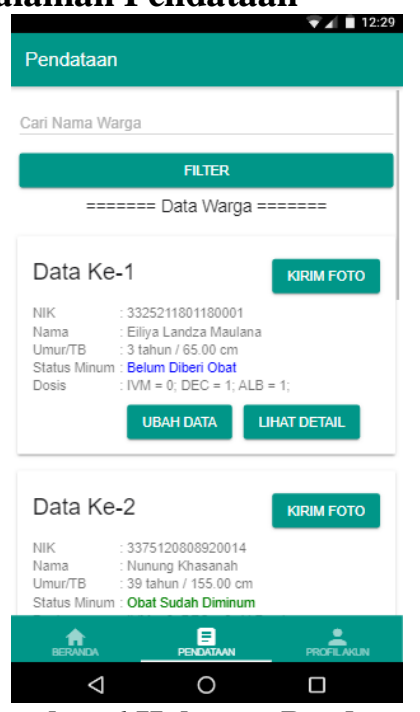

Gambar 6 Halaman Pendataan 
Halaman pendataan (lihat gambar 6) digunakan untuk mendata warga dalam meminum obat filariasis, melalui halaman ini kader TPE akan menginput pendataan, teramasuk foto warga pada saat meminum obat filariasi.

Pada halaman ini kader TPE akan melakukan validasi data terlebih dahulu sebelum memberikan obat filariasis. Jika data sudah valid, maka warga akan diberikan obat filariasis dan disuruh untuk minum di hadapan kader TPE.

Kader TPE akan secara langsung memantau warga untuk minum obat dengan cara mengambil gambar/memfoto warga. Hasil foto akan diunggah ke aplikasi dengan cara meng-klik tombol kirim foto.

\subsubsection{Halaman Ubah Data}
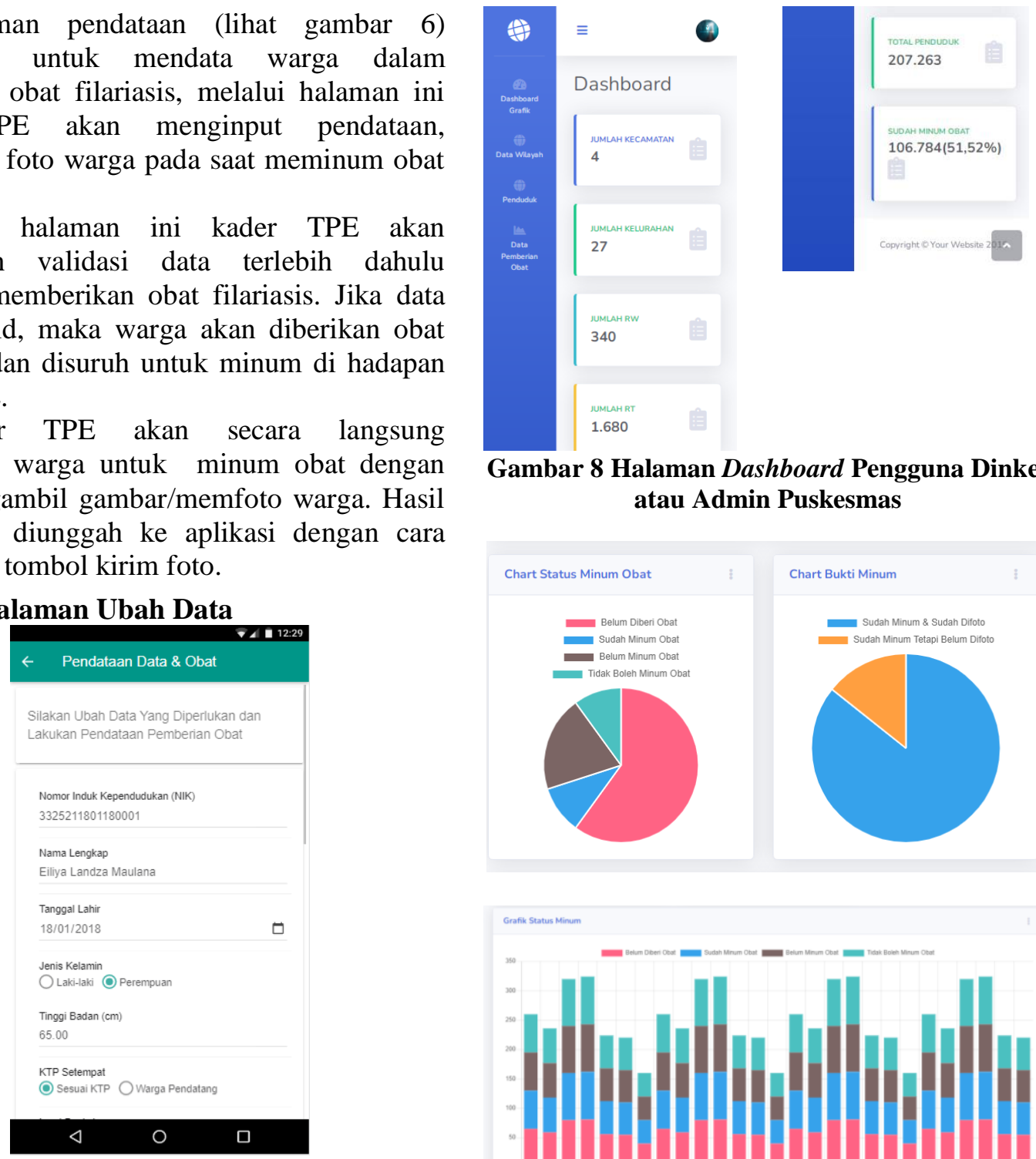

Gambar 8 Halaman Dashboard Pengguna Dinkes atau Admin Puskesmas

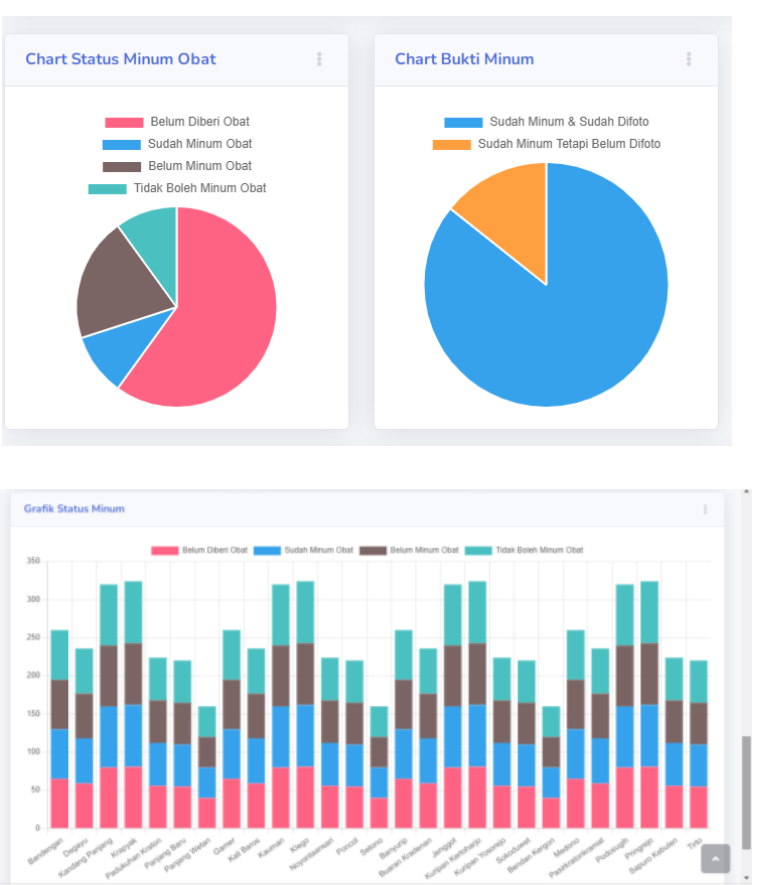

Gambar 9 Grafik Minum Obat

Halaman ubah data (lihat gambar 7) digunakan oleh kader TPE untuk mengubah data warga yang akan diberikan obat filariasis.

\subsubsection{Halaman untuk Pengguna Dinkes atau Admin Puskesmas}

Halaman dashboard berisi informasi data: 1) Jumlah Kecamatan; 2) Jumlah Kelurahan; 3 ) Jumlah RW; 4) Jumlah RT; 5) Total Penduduk; dan 6) Jumlah minum obat. Pada menu dashboard dapat dilihat infografis dari informasi data tersebut.

\subsection{Pengujian Aplikasi}

Pengujian aplikasi dilakukan setelah tahap pembangunan. Metode yang digunakan adalah alpha testing. Alpha testing atau pengujian alpha merupakan pengujian yang dilakukan oleh pengembang aplikasi. Pengujian alpha dilakukan dengan cara menguji fungsional sistem, yaitu:

\section{Tabel 3 Hasil Pengujian Sistem \\ No Test Case Hasil \\ 1 Menguji dengan metode Hasil dari peng create, update, delete (CRUD) ujian: sesuai setiap interface dengan inputan dengan yang yang dibutuhkan. diharapkan.}




\begin{tabular}{cll} 
No & \multicolumn{1}{c}{ Test Case } & \multicolumn{1}{c}{ Hasil } \\
2 & $\begin{array}{l}\text { Menguji database metode } \\
\text { create, update, delelte (CRUD) }\end{array}$ & $\begin{array}{l}\text { Hasil dari peng- } \\
\text { ujian: sesuai } \\
\text { dengan yang } \\
\text { diharapkan. }\end{array}$ \\
3 & $\begin{array}{l}\text { Menguji setiap interface } \\
\text { apakah dapat menampilkan } \\
\text { data dari database }\end{array}$ & $\begin{array}{l}\text { Hasil dari peng- } \\
\text { ujian: sesuai } \\
\text { dengan yang } \\
\text { diharapkan. }\end{array}$ \\
4 & $\begin{array}{l}\text { Menguji data API dari server } \\
\text { ke aplikasi }\end{array}$ & $\begin{array}{l}\text { Hasil dari peng- } \\
\text { ujian: sesuai } \\
\text { dengan yang } \\
\text { diharapkan. }\end{array}$ \\
&
\end{tabular}

\section{SIMPULAN DAN SARAN}

\subsection{Simpulan}

Berdasarkan hasil pengujian yang dilakukan terhadap sistem monitoring pemberian obat filariasis, maka dapat disimpulkan bahwa sistem sudah dapat memenuhi kebutuhan fungsional yang sudah diidentifikasi sebelumnya, yaitu: sistem dapat mendokumentasikan foto saat masyarakat meminum obat penyakit kaki gajah yang diberikan kader kesehatan setempat, sistem dapat menerima inputan data dari kader kesehatan setelah itu memfoto masyarakat saat meminum obat penyakit kaki gajah, sistem dapat menginformasikan keaktifan kader kesehatan dalam memberikan obat ke masyarakat, dan sistem dapat diakses dari berbagai perangkat, termasuk smartphone.

Aplikasi ini hanya dapat berjala di sistem operasi Android. Adapun versi Android yang minimal digunakan adalah Lolipop 5.0.

Keuntungan yang didapat dari aplikasi Dashboard Eksekutir RT/RW Filariasis, dibandingkan dengan sebelum menggunakan aplikasi Dashboard Eksekutir RT/RW Filariasis, yaitu: 1) Dinas Kesehatan memiliki data warga/masyrakat yang lebih akurat dibanding pada metode sebelumnya yang menggunakan data manual tidak terintegrasi pada database sistem; 2) pendataan warga lebih teratur dan terpusat dalam satu database. Data tersebut dapat dijadikan acuan dalam proses penentuan jumlah obat fialiriasis untuk kegiatan pada tahun berikutnya, sehingga dapat menekan biaya dalam proses pendataan; 3) Dinas Kesehatan dapat mengetahui jumlah warga yang telah meminum obat filariasis dan yang tidak meminum obat filariasis; 4) Dinas
Kesehatan dapat melakukan monitoring secara real-time I

\subsection{Saran}

Sistem yang berjalan belum dapat bersinergi dengan data kependudukan secara real-time, sehingga masih mengandalkan data yang diinputkan oleh operator/kader kesehatan, hal ini memberikan risiko adanya kesalahan pemasukan data, sehingga untuk waktunya selanjutnya, sistem ini dapat bersinergi dengan data kependudukan di Kota Pekalongan. Perlu adanya pelatihan yang lebih mendalam kepada Kader Tenaga Pelaksana Eliminasi (TPE), agar lebih terampil dalam mengoperasikan aplikasi tersebut.

Berdasarkan hasil penelitian yang dilakukan oleh Reza, dkk tentang "Analisis Kinerja Website Pemerintah Kota Pekalongan" (Maulana, Susanto, \& Binabar, 2021), maka untuk penerapan aplikasi dashboard RT/RW pada penelitian ini dibutuhkan kapasitas server yang besar. Hal ini dikarenakan adanya banyak data penduduk dan file foto yang cukup besar yang harus dikirim ke server.

Keberadaan sinyal atau jaringan internet yang baik dari sisi pengguna kader TPE sangat dibutuhkan agar proses upload data dapat berjalan dengan baik, dan data dapat tersimpan di database server.

\section{REFERENSI}

ATHO, M. A. (2018, Juli). Diambil kembali dari radarpekalongan.co.id: https://radarpekalongan.co.id/39655/ter nyata-kota-pekalongan-masih-endemiskaki-gajah/

BP, H. J., Ginandjar, P., Kusariana, N., \& Saraswati, L. D. (2019). Peran Tenaga Pelaksana Eliminasi dalam Pelaksanaan Program Pemberian Obat Secara Massal (POPM) Filariasis di Kota Pekalongan. Herlysse Jorghi BP / Media Kesehatan Masyarakat Indonesia, 18(1).

Dewi, Z. R., Ahmadi, C., \& Suardika, I. G. (2015). Dashboard Executive Information System Pada Banjar Berbasis Web. Jurnal Online Sistem 
Informasi (JOSINFO) Vol. 1, No. 1, Mei 2015, 1-9.

Dinkominfo Kota Pekalongan. (2017, Juli) Diambil kembali dari https://jatengprov.go.id/: https://jatengprov.go.id/beritadaerah/an gka-mikro-filariasis-lebih-1-pemkotakan-lakukan-pomp-ulang/

Henderi, Rahayu, S., \& Prasetyo, B. M. (2012). Dashboard Information System Berbasis Key Performance Indicator. Seminar Nasional Informatika 2012 (semnasIF 2012) (hal. d82-d87). Yogyakarta: UPN "Veteran" Yogyakarta.

Kurniawan, K., \& Ashari, A. (2015). Service Orchestration using Enterprise Service Bus for Real-time Government Executive Dashboard System. 2015 International Conference on Data and Software Engineering IEEE, 207-212.

Maulana, M. R., Susanto, E. B., \& Binabar, S. W. (2021). Analisis Kinerja Website Pemerintah Kota Pekalongan. Jurnal Litang Kota Pekalongan, Vol. 20 Tahun 2021, 48-54.

Maulana, M. R., Syaifudin, A., Budijanto, H. A., \& Susanto, E. B. (2021, Januari). Dashboard Eksekutif Sebagai Media
Koordinasi dan Monitoring Kegiatan Untuk Peningkatan Kinerja Aparatur Pemerintah. Jurnal Litbang Kota Pekalongan, 19, 47-54.

Sofyan, H., \& Nugroho, S. P. (2016). Pengembangan Academic Information Dashboard Executive (A-Index) Dengan Pentaho Data Integration Dan Qlikview (Studi Kasus : Prodi Teknik Informatika UPN "Veteran" Yogyakarta). Telematika, Vol. 13, No. 01, Januari, 2016, 17-22.

Susanto, B. (2019, Oktober). Diambil kembali dari https://jateng.tribunnews.com/: https://jateng.tribunnews.com/2019/10/ 23/terdapat-178-kasus-penyakit-kakigajah-di-kota-pekalongan

Turban, E. (2011). Decision Support and Business Intelligence System, 9th edition. New Jersey: Pearson Education Inc.

Yudiantara, P. O., Sukarsa, I. M., \& Sutramiani, N. P. (2019). Dashboard Executive Information System dengan Pendekatan Sistem Terdistribusi untuk Pemantauan Penyaluran Kredit KUR Mikro Bank X. Merpati Vol. 7, No. 1 April 2019, 6776. 